\title{
Acquiring Knowledge through Mobile Applications
}

\author{
http://dx.doi.org/10.3991/ijim.v9i3.4495 \\ H. Seyed Ebrahim ${ }^{1}$, K. Ezzadeen ${ }^{2}$ and A.K, Alhazmi ${ }^{2,3}$ \\ ${ }^{1}$ International Islamic University Malaysia, Kuala Lumpur, Malaysia \\ ${ }^{2}$ University of Science and Technology, Sana'a, Yemen \\ ${ }^{2}$ University Technology Malaysia, Johor, Malaysia
}

\begin{abstract}
The use of mobile devices is increasing to become an important part of daily life. This rapid growth has provided new platforms for a wide range of applications. In today's context, m-learning is considered the latest type of learning introduced as a result of this technological revolution, in which new learning options are provided through mobile applications. This paper presents a review of $\mathrm{m}$ learning and summarises the main advantages as well as the potential challenges of mobile learning through mobile applications.
\end{abstract}

Index Terms-m-Learning, Mobile Application, e-Learning, Social Networking

\section{INTRODUCTION}

Mobile technology is one of the most wide spread technologies that has integrated into everyday life in almost every country of the world. The development and the wide use of mobile technology motivates developers and vendors to develop a wide range of mobile applications.

Mobile applications (Mobile apps) can be defined as "software applications that are made for mobile phone operating systems that increase the capabilities of the cell phone by allowing users to do specific tasks" [1]. Different learning options are provided by mobile apps. There is a large number of mobile apps presently available. Fortunately, users can review most of the applications, making the selection of apps for particular topics easier due to the feedback they receive. Mobile apps can be in different educational forms including games, flash cards and knowledge sharing. It is interesting to check different kinds of apps for particular fields such as language learning and algebra, together with checking those apps that users give high ratings. The benefits of mobile apps include their easy development and broad accessibility [2]. Mobile apps are usually easy for students to refer to for their wishing to learn. The role that mobile technology plays in the life of students is very important [2]. This fact has been shown to be true in mobile app development. For example, Dragon Box, which is an m-learning app that teaches the basics of algebra, was heavily downloaded by users compared to other popular mobile applications such as Angry Birds. Based on the World Bank report named "Information and communication for development 2012: Maximizing Mobile", more than 30 billion mobile apps were downloaded in 2011, which mostly included software to extend the functionality of smart phones to become, for example, mobile wallets, navigational aids, or price checkers.

\section{EVALUATION OF MOBILE LEARNING}

Mobile learning or m-learning is often addressed as electronic learning. M-learning, in its initial definition, refers to learning utilizing mobile technology or the latest type of electronic learning [3]. Nevertheless, the development of mobile technology provided m-learning with its own proper identity.

Different researchers concentrate on the features of technology and pedagogy, as well as the social elements to classify mobile learning, to examine its relation with distance learning, electronic learning and mobile learning. Distance learning refers to the type of learning in which the student is physically away from the school or university. Distance learning existed before the technology boom that made the student able to become "connected" via the internet. Snail mail was the traditional way of communicating and exchanging information. E-learning is identified as online learning in most definitions [4]. Electronic learning in contrast to distance learning can be carried out on and off campus; however, it works differently in each context. Its location cannot restrict m-learning; it is available anywhere and anytime [5]. This means that $\mathrm{m}$ learning can be considered as e-learning's subset and electronic learning is a distance learning's subset (See Figure 1).

E-learning together with m-learning can be accessed by a larger number of students and provides greater access; therefore, a larger learning space is facilitated by these two [6].

The limitations associated with traditional e-learning systems and tools such as LMS raised the demands for new interactive, personalized and learner-centred learning systems [7]. The new transformation in using mobile technology and social media provide new alternatives toward more dynamic learning environment, which needs to be investigated and explored in further studies.

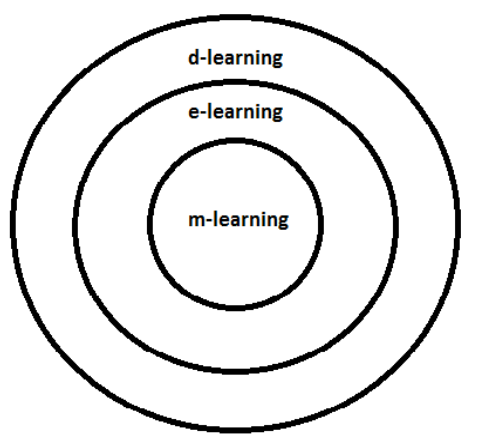

Figure 1. perspective of learning paradigms [5] 


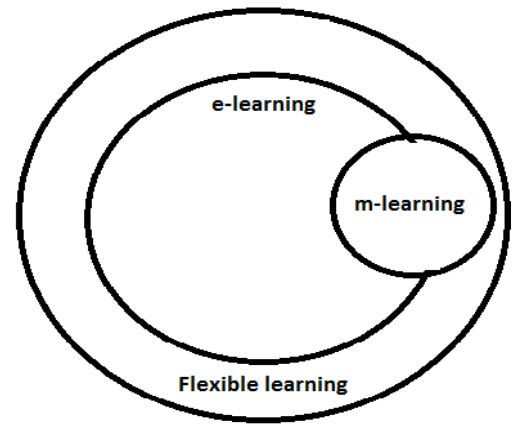

Figure 2. Relationship between electronic learning, mobile learning and flexible learning [6]

\section{Potential Benefits And TeChNOLOGICAL Advantages Mobile Learning Through MobiLe APPLICATIONS}

There are several benefits for mobile learning via mobile applications. According to [8] mobile learning has six purposes, 1) enhancing and building knowledge in any context; 2) allowing the collection of data specific to the present time and location; 3) acting as a path for learners to comprehend their unique paths of interest; 4) providing support by integrating work activities; 5) complementing other learning by supporting other learning tools and 6) integrating particular experiences as a part of a larger sum. Despite this, many people are inclined to use mobile devices for communication such as calls, texts, emails and social networking. [9] believes that mobile phones can help enhance socio-effect and social constructivist learning. In this study, the advantages of mobile learning are catagorized into four main advantages, namely: enhanced understanding of material content, cost effectiveness, game learning and informal learning.

\section{A. Enhanced understanding of material content}

The enhanced understanding of content can be one of the benefits of m-learning. According to [10], students are armed with an enhanced understanding and depth of knowledge concerning the content via various collaborative techniques and delivery methods. The utilization of mobile devices can enhance the motivation of students as they can participate in group discussions and dialogue more frequently and receive efficient quick feedback which improve learning and enhance retention of memory. According to[11], enhanced motivation to learn is directly related to the utilization of mobile device instead of the completed task.

Mobile devices can function as an evaluation tool for students and allow those who do not communicate much in class to express their opinions in a way that is easier and more comfortable for them to [10].

\section{B. Cost effectiveness}

Cost is one of the most important advantages of mobile learning through mobile applications [12]. Personal mobile devices are becoming prevalent and can be found everywhere, therefore suggesting that utilizing personal mobile devices in the classroom is becoming less expensive than buying laptops or textbooks. Researchers usually discuss the advantages of delivering course content and communication among students and teachers when describing how mobile phones can be utilized in the classroom [13].

\section{Game Learning}

Game learning has become of great interest among researchers and practitioners in recent years [14]. Some researchers believe that games on mobile phones have the ability to support social-affective learning as well as cognitive learning while developing strategic thinking, planning, negotiating skills, data handling, and communication [15]. Moreover, gaming has been proved to enhance intrinsic motivation which results in increased learning [16]. The utilization of educational applications in the classroom did not receive much attention and insufficient study. Smartphones using Android and iOS that have different downloadable applications have changed the way mobile devices can be used. Users can read books and be connected to social media through their phones. Moreover, there are a lot of educational applications that enable users to learn a new language and organize their home work, as well as and for other educational purposes.

\section{Informal Learning}

The popularity of smart mobile devices and related numerous mobile applications makes informal learning more interesting. Mobile learning has great prospects in the education domain, especially informal learning. Advancing technologies and new operating systems such as Android and iOS have applications that can be downloaded and have been revolutionary in the use of mobile phones. Apart from the traditional calls, mobile devices can also be used to connect to social networks, download and read e-books, provide books, pay bills and many other things. In addition to these uses, the App Store also holds a number of education related applications that allow learners to learn a language, interact and be aware of new projects, organize and set reminders for homework and much more.

In addition, many papers, books, and magazines have now started to feature QR (Quick Response) codes. These codes play a key role and impacts learning, and, in particular, informal learning. If users are interested in learning more information about a subject, they can instantly scan QR codes to redirect them to websites that will provide the needed information or receive more information about almost any specific subject which can be downloaded to the phone of the user.

\section{Mobile Computing Applications And Social MEDIA}

There are a number of mobile applications available through social networking sites. Social networking sites offer a wide variety of opportunities to support student engagement and student learning [17], [18], [19]. The traditional e-learning and its tools such as LMS, limit the learning opportunities for student-student interaction and student-teacher interaction [7]. As stated in [17], [19] reports that interactive and communication features of SNSs have succeeded in attracting the attention of the majority of students in colleges and universities.

This part focuses on three main themes revolving around mobile computing applications and social media that have been prominent in existing literature. The three themes are the engagement of learning via networks and connectivity, the ability to nurture a team spirit towards learning and thirdly to ensure the authenticity and level of genuine learning that takes place. 


\section{A. Engaging learners with constant connectivity}

Mobile technologies are those that have the capability of allowing people to not only communicate with each other at any time, but also act as a source as a database for valuable content that can benefit students, for instance, to learn through a new medium [20]. Furthermore, [21] asserts that mobile devices can allow learners to look for, recognize, manipulate and analyse existing knowledge, thus increasing the scope of their own knowledge by utilizing this enhanced base as to perform their tasks.

The consequences of learning by means of mobile devices has emphasized the role of social media, where learners create a virtual forum to share and discuss content [18], [22]. For example, Wikipedia or certain blogs are result from combining user knowledge. Basically, such online projects allow the knowledge and efforts of the group known as "collective intelligence" [23] to be enhanced and shared, thereby increasing the scope, quality and quantity of information, which is usually far superior than the contribution of a single individual [24]. The concept of collective intelligence, coined by Levy, defines an environment that facilitates participative learning and teaching, thus enhancing and nurturing new ideas that originate from cyberspace. One of the most important features of learning by means of mobile devices is the availability of constant connectivity, as this enables the students to engage themselves regularly in creating content and being evaluated by other learners, which, in turn, creates a learner-centric environment [25]. [26] carried out a research on the use of Facebook to advocate learning and found that it supported learning by increasing the interaction and relationship between students and faculty members.

\section{B. Fostering collaborative learning}

Mobile technologies facilitate learning by creating an environment in which both learners and instructors are given the opportunity to freely discuss, analyse, and collaborate with each other. In addition, it was reported that social media is another platform that helps students engage in collaborative learning in an informal setting [27], [19]. [28] discovered the usefulness of mobile devices in a project-centred course which allowed the students and the instructors to interact with each other in a variety of ways such as text messages, emails and blog posts on the latest updates, using both text and photographs to communicate better. Hence, social media proved it allowed students to interact and build constructive relationships and resulted in an increased quality of learning [28], [29], [17].

\section{Enabling authentic learning}

[30] expresses that learning needs to be complimented with mobility as it not just provides information but allows learners to apply it to different contexts. The majority of applications on mobile devices are a part of social media that allow learners to share content in a plethora of wars other than merely text, including photos, audio and videos, geotags that show the geographical location of a person, microblogs which contain short sentences or images to convey messages, and other social networking sites that allow learners to connect and communicate with their peers and other professionals. In sum, the use of mobile devices and their social media applications have proven to create a customized and a genuine learning experience [31].

\section{Potential Challenges}

One main difficulty of this study is not being able to keep pace with technological developments. While most existing studies provide promising results, technical advancements are evolving so fast that their true potential in the educational realm has been difficult to ascertain. Consequently, we have yet to determine the true potential of enhanced mobile devices such as smartphones and personal m-gadgets (mobile) for educational, casual learning, which presently prevails in classrooms, as well as educational outcomes of full fledge activities or research of a longitudinal nature. There are number of crucial issues related to using technology in education, which include theoretical, pedagogical, and technological elements. From a technological perspective, usability, flexibility, and interactivity are essential to successfully integrate technology into educational settings; however, pedagogical elements are also important [7]. Pedagogical issues have an impact, both direct and indirect, on the role the system plays to enhance the teaching and learning process. These factors need to be considered to improve the use of technology to support education [7].

Although m-learning offers many apparent benefits, it also suffers from several significance issues. The challenges to m-education and m-learning below were identified by [32]: that are related to major issues in $\mathrm{m}$ education and m-learning:

- Mobility: m-learning provides anywhere/anytime learning, both within and outside of classrooms. This represents a challenge for conventional or traditional educational settings.

- Informality: Mobile learning technologies are more casual in nature and hence can lose some of its gains if it is used too widespread.

- Ownership: Mobile technologies offer personal access as well as ownership for supporting personal as well as group studies. Personal ownership is crucial for commitment as well as engagement, but it poses a challenge in terms of institutional control.

Various other traits related to the ubiquity of m-gadgets are also seen as by some of the scholars as possible challenges. For instance, the smaller size of the m-gadgets allows the mobility and portability for them to be used anywhere and anytime. In addition, there are some challenges that are associated with technical issues. Some studies have shown that one drawback to learning by means of mobile phones could be the size of the screen. [33] analysed learning and screen sizes and found that learning was better when the size of the screen was at least $58 \mathrm{~mm}$ (2.28in) diagonally. Furthermore, the study also showed that the opinion of students did not differ significantly regarding the screen size and its impact on learning. In addition, it is important to note that tablets act as an alternative to mobile phones and laptops and eliminate the challenges of using mobile phones for learning.

It is important to consider the infrastructure of the school as well as the level of teacher training if implement mobile learning is to be implemented. Another drawback to mobile learning is the other personal uses of the device with less control over them. [14] also notes the barriers related to the different operating systems for mobile learning. Another concern related to mobile learning is that the virtual environment can hinder the real-life interactions of humans [34]. 


\section{CONCLUSION}

There is a growing awareness of mobile technology and mobile applications in education. In this paper, a review of mobile learning, the advantages of mobile applications in education, and the challenges of using mobile technologies were presented. The benefits of mobile computing applications and social media were also presented and discussed. Four main advantages of using mobile applications in education were also discussed: first, enhanced understanding of material content; second, cost effectiveness; third, game learning; fourth, informal learning. The main advantages of the mobile applications in social media have been summarised in this paper into: engaging learners with constant connectivity, fostering collaborative learning, and enable authentic learning. On the other hand, the potential challenges are related to some issues including, the mobility and large geographic areas, control and evaluating informal learning practices, less control over the personal use, and the technical issues related to the design of the mobile devices to support convenient learning. Overall, the paper presents insights for the use of mobile applications in learning environments, which can lead to further investigation of the effective use of $\mathrm{m}$ learning and related factors with students and teachers in learning environments.

\section{REFERENCES}

[1] A. Linhart et al., "Social Media and Mobile Internet Use Among Teens and Young Adults," Pew Internet and American Life Project, 2010.

[2] S. Jackson et al., "Panel: mobile application development in computing curricula." pp. 107-108.

[3] R. Doneva, N. Kasakliev, and G. Totkov, "Towards mobile university campuses," 2007.

[4] M. J. Rosenberg, "E-learning: Strategies for Delivering Knowledge in the Digital," Mcgraw-2001, 2001.

[5] T. Georgiev, E. Georgieva, and A. Smrikarov, "M-Learning: A new stage of E-Learning." pp. 1-5.

[6] L. Low, and M. O’Connell, "Learner-centric design of digital mobile learning." pp. 71-82.

[7] A.K. Alhazmi and A.A. Rahman, "Why LMS failed to support student learning in higher education institutions," E-Learning, EManagement and E-Services (IS3e), 2012 IEEE Symposium, 2012. http://dx.doi.org/10.1109/IS3e.2012.6414943

[8] M. Sharples, "Big issues in mobile learning," 2006.

[9] J. Colley, and G. Stead, "Take a bite: producing accessible learning materials for mobile devices," learning with mobiledevices, pp. 43, 2004.

[10] Nikana, "Co-operative group work," Collaborative Learning, January 2000.

[11] T. A. Goodison, "The Implementation of M-learning in UK Higher Education." pp. 613-618.

[12] P. Pollara, "Mobile learning in Higher Education: A glimpse and a comparison of student and faculty readiness, attitudes and perceptions," Duquesne University, 2011.

[13] A. Najmi, and J. Lee, "Why and How Mobile Learning Can Make a Difference in the K-16 Classroom?." pp. 2903-2910.

[14] J. Kadirire, and R. Guy, "Mobile learning demystified," The evolution of mobile teaching and learning, pp. 15-56, 2009.

[15] A. Mitchell, "Exploring the potential of a games-oriented implementation for m-portal," learning with mobiledevices, pp. 105, 2004.

[16] M. R. Lepper, and D. I. Cordova, "A desire to be taught: Instructional consequences of intrinsic motivation," Motivation and emotion, vol. 16, no. 3, pp. 187-208, 1992. http://dx.doi.org/10.1007/ $\underline{B F 00991651}$
[17] A.K. Alhazmi and A.A. Rahman, "A Framework for Student Engagement in Social Networking Sites" (2014). PACIS 2014 Proceedings. Paper 50. http://aisel.aisnet.org/pacis2014/50.

[18] A.K. Alhazmi and A.A. Rahman, "Facebook in Higher Education: Students' Use and Perceptions," AISS: Advances in Information Sciences and Service Sciences, vol. 5, 2013, pp. $32 \sim 41$.

[19] A.K. Alhazmi, A.A. Rahman, H. Zafar, "Conceptual model for the academic use of Social Networking Sites from student engagement perspective," e-Learning, e-Management and e-Services (IC3e), 2014 IEEE Conference on. http://dx.doi.org/10.1109/ IC3e.2014.7081232

[20] N. Cavus, H. Bicen, and U. Akcil, "The Opinions of Information Technology Students on Using Mobile Learning," Online Submission, 2008.

[21] T. H. Brown, "Towards a model for m-learning in Africa," International Journal on E-learning, vol. 4, no. 3, pp. 299-315, 2005.

[22] E. Agichtein et al., "Finding high-quality content in social media." pp. 183-194.

[23] J. Surowiecki, The wisdom of crowds: Anchor, 2005.

[24] A. M. Kaplan, and M. Haenlein, "Users of the world, unite! The challenges and opportunities of Social Media," Business horizons, vol. 53, no. 1, pp. 59-68, 2010. http://dx.doi.org/10.1016/ j.bushor.2009.09.003

[25] J.-H. Valk, A. T. Rashid, and L. Elder, "Using mobile phones to improve educational outcomes: An analysis of evidence from Asia," The International Review of Research in Open and Distributed Learning, vol. 11, no. 1, pp. 117-140, 2010.

[26] M. D. Roblyer et al., "Findings on Facebook in higher education: A comparison of college faculty and student uses and perceptions of social networking sites," Internet and Higher Education, vol. 13, no. 3, pp. 134-140, //, 2010.

[27] A.K. Alhazmi and A.A Rahman, Facebook in Higher Education: Social and Academic Purposes, INTERNATIONAL JOURNAL OF COMPUTERS \& TECHNOLOGY, vol. 12, 2013, pp. 33003305. http://cirworld.org/journals/index.php/ijct/article/view/3444.

[28] T. Cochrane, and R. Bateman, "Smartphones give you wings: Pedagogical affordances of mobile Web 2.0," Australasian Journal of Educational Technology, vol. 26, no. 1, 2010.

[29] E. S. Hoffman, "Social media and learning environments: Shifting perspectives on the locus of control," in education, vol. 15, no. 2 , 2013.

[30] M. Ruta et al., "A knowledge-based framework for e-learning in heterogeneous pervasive environments," Multiplatform ELearning Systems and Technologies: Mobile Devices for Ubiquitous ICT-Based Education: Mobile Devices for Ubiquitous ICTBased Education, pp. 20, 2009.

[31] L. Archambault et al., "Professional development 2.0: Transforming teacher education pedagogy with 21 st century tools," Journal of Digital Learning in Teacher Education, vol. 27, no. 1, pp. 4-11, 2010. http://dx.doi.org/10.1080/21532974.2010.10784651

[32] N. Futurelab et al., "Literature Review in Mobile Technologies and Learning," 2004.

[33] N. Maniar, "M-learning to teach university students." pp. 881-887.

[34] E. Dieterle, C. Dede, and K. Schrier, "Neomillennial" learning styles propagated by wireless handheld devices," Ubiquitous and pervasive knowledge and learning management: Semantics, social networking and new media to their full potential, pp. 35-66, 2007.

\section{AUTHORS}

H. Seyed Ebrahim is with the International Islamic University Malaysia, Kuala Lumpur, Malaysia (hosseini.qalati@gmail.com).

K. Ezzadeen is with the University of Science and Technology, Sana'a, Yemen (k.ezzadeen@ust.edu).

A. K. Alhazmi is with the University Technology Malaysia, Johor, Malaysia ( abdulsalamkaed@gmail.com).

This work was supported by Wisdom and Knowledge Club ,Supreme Council for Sunni Islamic Institute in South of Iran (Malaysia Office IIUM),Grant No: SCSIIRG Program, WKC-15002-9436. Submitted 25 February 2015. Published as resubmitted by the authors 18 May 2015. 